\title{
The Evolving Information Needs and Behaviors of Undergraduates
}

Brianna Limas

San Jose State University; UC Irvine, brianna.limas@sjsu.edu

Follow this and additional works at: https://scholarworks.sjsu.edu/ischoolsrj

Part of the Higher Education Commons, and the Information Literacy Commons

\section{Acknowledgements}

This literature review was adapted from a research paper written originally in Professor Ellen Greenblatt's course on Information Communities. Special thanks for her edits, suggestions, and encouragement. She is in the author's memory as a wonderful and impactful instructor whose passion and thoughtful comments was a driving force in this paper. In addition, this author would like to note that this review was researched, written, and submitted for publication before the onset of the COVID-19 pandemic. As one of the SRJ editors pointed out, the question, "what are the information needs and behaviors of undergraduates?" has an even greater weight and importance now, with even more unknown factors and new permutations. There is now a greater emphasis on themes around emerging technologies, social media, and misinformation that makes the argument for improved (and decidedly critical) information literacy for undergraduates more emphatic, to a degree far beyond the scope of what this paper had set out to do. In a way, this literature review is already outdated; but hopefully, it can help bridge the gap between the research done and the much-needed work going forward.

\section{Recommended Citation}

Limas, B. (2020). The Evolving Information Needs and Behaviors of Undergraduates. School of Information Student Research Journal, 10(2). https://doi.org/10.31979/2575-2499.100203 Retrieved from https://scholarworks.sjsu.edu/ischoolsrj/vol10/iss2/3

This article is brought to you by the open access Journals at SJSU ScholarWorks. It has been accepted for inclusion in School of Information Student Research Journal by an authorized administrator of SJSU ScholarWorks. For more information, please contact scholarworks@sjsu.edu. 


\title{
The Evolving Information Needs and Behaviors of Undergraduates
}

\author{
Abstract \\ Undergraduates comprise a highly complex information community, composed of many identities and \\ with a range of interests and skills. Emerging technologies continue to play a critical role in \\ undergraduates' information behaviors. While prior literature has focused on the academic information \\ needs of students, emerging technologies have brought to light the considerable role of their everyday life \\ information behaviors. This paper seeks to explore the information needs and behaviors of \\ undergraduates, in particular the current and incoming graduating classes. With increased focus on \\ meeting everyday life information needs and continued appreciation and understanding of the versatility \\ of emerging technologies in the lives of undergraduates, libraries will increase their value to this \\ information community and better meet their needs.
}

\section{Keywords}

undergraduates, information literacy, emerging technologies, social media, academic libraries, information behaviors

\section{Acknowledgements}

This literature review was adapted from a research paper written originally in Professor Ellen Greenblatt's course on Information Communities. Special thanks for her edits, suggestions, and encouragement. She is in the author's memory as a wonderful and impactful instructor whose passion and thoughtful comments was a driving force in this paper. In addition, this author would like to note that this review was researched, written, and submitted for publication before the onset of the COVID-19 pandemic. As one of the SRJ editors pointed out, the question, "what are the information needs and behaviors of undergraduates?" has an even greater weight and importance now, with even more unknown factors and new permutations. There is now a greater emphasis on themes around emerging technologies, social media, and misinformation that makes the argument for improved (and decidedly critical) information literacy for undergraduates more emphatic, to a degree far beyond the scope of what this paper had set out to do. In a way, this literature review is already outdated; but hopefully, it can help bridge the gap between the research done and the much-needed work going forward.

\section{About Author}

Brianna Limas (she/they) is an SJSU MLIS student and Spectrum Scholar focusing on academic libraries and information intermediation. 
Undergraduates, as an information community, constitute a wide array of identities, characteristics, and subgroups. There are a wide multiplicity of factors within the broader community of "undergraduates" one might consider: international students, DREAMers and immigrant students, LGBTQI+, students who are also parents, homeless students, students with disabilities, students from low-income backgrounds, humanities students, STEM students, art students, undeclared students, off-campus students, students in particular residence halls, students in fraternal organizations, and etc., ad infinitum. Few of these identities is mutually exclusive, and each one of these intersections might constitute an individual network of information-seekers. As such, undergraduates comprise a highly complex information community. More pressingly, studies have demonstrated that undergraduates are extremely novice researchers (Karas \& Green, 2007), but that receiving help and support from the library and its staff can drastically increase the information retention of students and their professional success after graduation (Palumbo, 2016). It is therefore critical that information intermediators and library staff can address the multifaceted information needs of a manifold information community.

As Fisher and Bishop (2015) explain, drawing from Christen and Levinson's four key angles of community, a single subset of undergraduates represents how communities can live and grow out of multiple dimensions of relatedness (e.g., departments, dorms, or extracurricular interests). For the undergraduate, their complex identities, overlapping associations and interests, questions about the future, and new explorations of self, set the stage for excitement as well as confusion and anxiety - all layered on top of their academic and scholarly pursuits. With these feelings, of course, come questions. Understanding the ever-changing information needs and behaviors of undergraduates requires a deeper understanding of their cohesion as an information community. This makes research into the information needs and behaviors of undergraduates, as a whole, integral to the success of both the students and the institutions that serve them.

Researching undergraduates requires a sensitivity and awareness to the multivalence of this group, but also a broader sense of the larger information needs and trends. In order to better understand the entire network of information flow and information behaviors prevalent throughout a campus community (which now also includes its online and distance learning community), undergraduates' information needs can be looked at according to the technologies they use. This includes the technological, digital, and informational developments and challenges that are pertinent to a class during their time of study. An academic librarian working today certainly considers the information needs and behaviors of undergraduates within the context of Web 2.0 technologies, threats to digital privacy, and the proliferation of "fake news" and the need for increased information and critical information literacy training.

Emerging technologies play a tremendous role in the information needs and behaviors of undergraduates. At the same time, for information professionals and librarians in service to this community, there remain ever-complicating ethical and legal issues. This paper seeks to explore the information needs and behaviors of undergraduates, in particular the current and incoming graduating classes. A review of the current literature is followed by a description of the methodology used in secondary research on undergraduates, an analysis of the types of information needs and behaviors of undergraduates, and suggestions for future research. Finally, this paper will explore possible approaches to serving and meeting the information needs of today's and tomorrow's undergraduates.

\section{Literature Review}


Much of the research focusing on the information needs and behaviors of undergraduates is published by academic librarians and researchers working in the field. Both scholarly and professional approaches are common when writing about undergraduates. The literature reviewed here has been written using scholarly methodologies; however, several cornerstone professional writings, such as the Association of College and Research Library's Standards for libraries in higher education (2012) and Framework for information literacy for higher education (2015), have been reviewed. Methodologies tend to include a mix of qualitative and quantitative data. The theoretical framework of information search process, formulated by Kulthi (1991), often comes into play, as does Bates's (2010) theories on 'berrypicking' as information behavior.

Much of the research conducted on undergraduates has found that one of the greatest challenges they face in successful information-seeking is time. In attempting to use what is perceived to be the quickest and most accessible resources, these new researchers often omit print resources or other opportunities for discovery (Karas \& Green, 2007). Another major issue in the information behavior of undergraduates is their level of information literacy, as undergraduates typically will either neglect to fact check or may purposefully leave out information that challenges their original assumptions or beliefs (Karas \& Green, 2007; Whitmire, 2004). With increasing frequency, undergraduates and their generational cohort gather and create information via the internet, social media, and other technologies. When doing research, many assume that this will be adequate and will avoid the library altogether (Karas \& Green, 2007). In the era of "fake news" and digital "echo chambers," information literacy is not only a critical research skill for undergraduates' academic success, but a life skill.

Due to the prevalence of social media, web-based information behavior, and other emerging technologies, the literature tends to focus on these particular aspects of undergraduates' information behavior. One of the common themes addressed in the research is concerned with undergraduates' information literacy, especially online and on specific platforms. For example, studies have been conducted looking specifically at the information behavior of undergraduate students using Google (Georgas, 2013), Twitter (Hassan, 2017), and Wikipedia (Selwyn \& Gorard, 2016). Another common approach is to address how undergraduates seek out information across multiple platforms and contexts, and the criteria they use to establish validity (Karas \& Green, 2007; Nicholas et al., 2009; Whitmire, 2004). Trembach and Deng (2018) found in their study concerning information literacy instruction that millennial and Gen $\mathrm{Z}$ learning styles need to be better understood and incorporated into information instruction design.

Because of the primacy of the researchers' professional interests-teaching information literacy in a scholarly context - a concern for everyday information behavior only briefly emerges in the later literature. Indeed, Kim et al. (2014) conclude that information literacy-as a concept and as a standard for library instruction - must now extend "beyond simplistic and technical knowhow" (p. 444) by going outside the bounds of purely academic information behavior. While some of these studies have attempted this (Georgas, 2013; Hassan, 2017; Kim et al., 2014), additional research on the non-academic information behavior of undergraduates would contribute to a "holistic approach," which has been prescribed by Trembach and Deng (2018).

\section{Methodology}

In order to gain a foundational understanding of undergraduates as an information community, secondary searches focused on information behaviors of undergraduate students as a general category. Most queries were conducted in peer-reviewed journal databases, and most of the research on which this paper is built was found in journals related to library science and academic libraries. Additionally, as cornerstones designed to guide the information service provided to 
undergraduates, papers from the Association of College and Research Libraries (ACRL) were also included.

Academic librarianship is a well-established field within the information professions, and colleges and universities play a critical role in our social fabric. As a result, there is abundant research on undergraduates. Because of the fast-changing nature of the field and dynamics of this information community, this research has attempted to focus, where possible, on work produced in the last 5-10 years that is focused on emerging technologies, social media, and information literacy. The majority of the articles included have been published within the last 10 years, with the notable exception of some earlier foundational studies.

Academic papers and research studies were evaluated and compared in order to identify emerging trends in undergraduate information needs and behavior. This comparative and analytical approach was effective in assessing current services to undergraduates. Different models of the role of the internet versus traditional library services also become apparent. However, there remains a need for increased study in everyday life information behaviors.

Community-based information sources were also evaluated. Research on undergraduate information-seeking behaviors indicated that social networking sites like Twitter, YouTube, and Wikipedia are prominent in their popularity with undergraduates (Kim et al., 2014). Using this information, the author was able to explore these platforms for trending topics and popular accounts. As the undergraduate information community is extremely broad and includes a wide range of interests, it would be extremely difficult to pinpoint, for example, the most popular hashtags amongst undergraduates. This made narrowing down community-based information sources initially very difficult. After more careful evaluation of these platforms, this review of social media platforms was conducted through hashtags and social networking site pages that focused on topics relevant to issues that affect undergraduates in particular, such as student debt and school campus selection. As Hassan (2017) writes in his study of undergraduates on Twitter, hashtags promoting activism, social justice, and civic engagement, such as \#blacklivesmatter, are also integral to the information behaviors of many undergraduates. This process revealed that patterns and trends in undergraduates' engagement in community-based information sources can be difficult to anticipate and are subject to change according to the specific needs and cultural contexts of an individual student.

\section{Discussion}

\section{Information Needs and Behaviors}

Undergraduates are novice researchers who often are prone to being overconfident in their abilities to find information and evaluate its credibility. Often, undergraduates neglect library professionals and resources in the course of their studies; as a result, they miss out on valuable and useful information. Karas and Green (2008) found that students usually "fail to recognize that they may not have been researching properly" (p. 104) when obstacles arise in the research process.

At the same time, today's undergraduate student body-generationally speaking, mostly comprised of millennials and Gen Z'ers - are regarded as being highly tech-savvy and active on social networking sites (Kim et al., 2014). Their engagement online fits a number of information behavior models. Research on undergraduates' use and participation in the information activities of social media and the Internet are reinforced by Bates's model of 'berrypicking' (Bates, 2010, "History" section). Additionally, many of the formats and features of popular social networking sites can help undergraduates engage in "information encountering" (Erdelez, 1999). By contrast, the information behavior of undergraduates engaging in academic research and course-related information-seeking more closely aligns with other theoretical models. 
Many of the scholastic information needs of undergraduates seem to correlate to Belkin's model of an 'anomalous state of knowledge' (Bates, 2010, "History" section), as they require extensive description that might not be readily accessible to new researchers like undergraduates. Another relevant model of understanding information needs would be Kuhlthau's Information Search Process Model, especially as it pertains to students" "conceptualization of a paper or project" as being "bound up in confusions and problems in searching for information" (Bates, 2010, "History" section). These two aspects of undergraduates' information needs - the academic, and the everyday - necessitate very different approaches in understanding and evaluating the information behaviors of undergraduates.

\section{Academic Information Needs}

While undergraduates' skill with emerging technologies is worthy of note, their primary objectives as students will be to successfully complete course assignments and, hopefully, pursue their intellectual interests with competence. Their familiarity with emerging technologies may obscure their own ability to self-assess their information needs and identify gaps in the information-seeking behaviors and strategies. When surveyed, undergraduate students often rate their research skills very highly, even while rating skills that they admittedly lack just as high (Nicholas et al., 2009).

In her 2004 study, Etheline Whitmire found that a student's ability to synthesize conflicting information found online rested highly on their epistemological beliefs and reflective judgment. That is, those students who had a highly-developed attitude toward knowledge were better able to assess and utilize information from various sources, and those students with higher levels of reflective judgment had stronger criteria for assessing a source's credibility. At the same time, Trembach and Deng (2018), in their review of the literature concerning information literacy instruction, found that Gen Y learning styles need to be better understood and incorporated into information instruction design. These findings would suggest that there is a wide array of factorsboth individual, as with epistemological beliefs and reflective judgment, and culturalgenerational - that influence the informational literacy and research skills of undergraduates.

At the same time, this "novice" level information community has developed several highly useful and effective information behaviors. In their everyday life information behavior, undergraduates are part of a generation of technology users and information seekers that are extremely adept. When applying their online skills to their academic work, there is evidence that undergraduates have developed a number of successful strategies. Selwyn and Gorard (2016) surveyed Australian students from public and private colleges and found that undergraduates made frequent use of Wikipedia, but recognized its limitations as a scholarly source. Instead, they used social networking service (SNS) as a study aid and as a jumping-off point to better understand a difficult topic. According to Selwyn and Gorard, Wikipedia also proved helpful for English-learner students.

Georgas's (2013) research assessing students' attitudes towards Google compared to library-based federated searching explores many of the dynamics at play when looking at undergraduates' information behavior. Georgas surveyed students at the City University of New York, Brooklyn and found that students' preference for Google was largely based on design. In fact, Georgas uses students' survey responses to conclude that many students actually prefer library sources in many instances. The pull towards Google as a more frequent go-to for information was based on "efficiency and ease of use, but they recognize...Google's limitations" (p. 181). While concerns for students' information literacy online is justified, it should also take into consideration the vast arsenal of effective, useful techniques that millennials and Gen Y'ers have developed for themselves. 


\section{Everyday Life Information Needs}

There is new and growing interest in studying the everyday information needs and behaviors of undergraduates, particularly as it plays out across emerging technologies. Without a doubt, there is tremendous overlap between a student's "academic" and "everyday" life. However, traditional studies of undergraduates tend to regard undergraduate information behavior as activities that pertain directly towards that student's coursework. Yet a survey of the types of content being created, shared, and accessed by undergraduates (and soon-to-be undergraduates) reveals deeper layers of their information behavior.

For example, a growing trend on YouTube, a popular site amongst undergraduates (Kim et al., 2014), is videos that reveal campus "hotspots," tour dorm rooms, or in which community members discuss which college they will attend and why they chose it (Go Beyond The Brochure, 2015). YouTube could be a useful tool in helping a freshman or transfer student learn how to navigate their new environment, as well as satisfying other information needs.

Additionally, Hassan (2017) looked at African and African-American students on Twitter and concluded that this SNS has the potential for highly positive information behavior for students, noting uses for mental health access and democratic activism. In their 2014 survey of undergraduates' social media use, Kim et al. describe the usefulness of SNS as platforms for collaborative information sharing, creation, and identifying local news stories not presented in mainstream media outlets. They conclude, "If used properly and with care, social media can be powerful and transformative tools" (Kim et al., 2014, p. 444). Contrary to some of the more alarmist sentiments regarding emerging technologies, their incorporation into the information behaviors of undergraduates represents an exciting opportunity to encounter and exchange useful information in new, transformative ways.

\section{Information Literacy}

Nonetheless, social media and networking sites present new, hefty challenges to information literacy. Kim et al. (2014) point out that the one-click sharing features of many social networking sites drastically increase the dissemination of misinformation. As a result, new approaches in teaching and evaluating information literacy instruction are required in order to address the evolving needs and behaviors of undergraduates. The availability of digital resources for undergraduates has allowed increased access to information. However, this information community, while highly adept in some ways, still lacks some of the basic skills for information literacy (Karas \& Green, 2007; Kim et al., 2014; Whitmire, 2004).

Newer research on the information behaviors of undergraduates contains strong recommendations for incorporating emerging technologies into information literacy instruction, rather than struggling against them. Georgas (2013) expresses the need to introduce higher-level information literacy skills but also "revisit some lower-level information literacy skills as well," (p. 181) such as unpacking citations and identifying types of information sources. A new school of thought seems to unfold here: emerging technologies and SNS, rather than being purely detrimental to information literacy and undergraduates' information behavior, can be better understood and used by information professionals to teach information literacy skills. Design, user experience, and a holistic understanding of information behaviors (not just information-seeking) are integral to this approach to information literacy and information behavior. Kim et al. (2014) suggest that the rise of emerging technologies, with both their obstacles and benefits, have created a new opportunity to redesign information literacy for undergraduates - one that better understands everyday-life information-seeking. 
As information professionals seek to better understand the learning styles and epistemological beliefs of students (Trembach \& Deng, 2018; Whitmire, 2004), so should they attempt to better understand the challenges and possibilities presented by emerging technologies. Georgas (2013) recommends that library search tools emulate Google in their design and functionality; Selwyn and Gorard (2016) suggest that classrooms and libraries can teach students how to not only assess but contribute to information on Wikipedia; Hassan (2017) advocates for the vital role that SNS play in information communities and promotes Twitter as a tool to enhance student-professor communication. To go further, Nicholas et al. (2009) have advocated for a focus on "Virtual Scholar studies;" their research points to the growing importance of design and indepth understanding of the vast tools of the internet when approaching information literacy.

\section{Conclusion}

As the information community of undergraduates includes a broad, complex body of various identities and interests, so too do their information needs and behaviors range from the fixedly academic, to the eclectic and everyday life. Researching a thesis, learning how to properly cite a source, or understanding career options in their major remain constant information needs for this community, even with the generational changes, individual interests, or shifts in technology. While this scholarly focus continues to be of primary interest for academic librarians serving undergraduates, the interplay of their everyday information needs and the role of emerging technologies play an increasingly vital part in how undergraduates engage with information and their information behavior.

In fact, scholarly institutions and information professionals might do well to learn from SNS and emerging technologies in order to better serve undergraduates, while striving to take a "holistic approach" to meeting information needs (Tremback \& Deng, 2018). While more research is needed in order to better understand the everyday life information needs and behaviors of undergraduates, a number of libraries have already begun to consider the whole student and their everyday life in order to better serve all of their information needs. In a study of effective academic library outreach strategies, librarian Carrie Girton (2018) discusses the effectiveness of "empathetic marketing." This strategy includes promotional outreach of library services that is contextualized in an understanding of issues that might be affecting the student body. For example, library promotions might speak to understanding the pressures of finals or the difficulties of being a distance learner (Girton, 2018). Such strategies help to bridge the gap between academic and everyday life information needs, making the library a more available and relevant information resource for undergraduates.

Academic libraries have historically been, and continue to be, cornerstone fixtures in the intellectual lives and success of undergraduates. However, as emerging technologies and other socio-cultural factors press in and continue to change our social fabric, so too must academic libraries adapt and evolve in order to remain relevant and accessible in the lives of students. While many libraries have done exceedingly well in updating their physical and virtual spaces, expanding online databases, and using new technologies, one of the most pressing needs is a deeper, more complex understanding of the everyday life information needs and behaviors of undergraduates.

In order to meet the wide-ranging information needs of undergraduates, academic libraries and librarians must become readily adaptable. Additionally, we must present ourselves as relevant to more than their strictly course-related activities. By doing so, libraries and academic librarians will be better situated to engage with undergraduates on the needs they do not even realize they have, such as developing their information literacy and research skills. With increased focus on meeting everyday life information needs and continued appreciation and understanding of the 
versatility of emerging technologies in the lives of undergraduates, libraries will increase their value to this information community.

\section{References}

Association of College and Research Libraries. (2012). Standards for libraries in higher education: Approved by the ACRL Board of Directors, October 2011. College \& Research Libraries News, 73(1), 34-48. https://doi.org/10.5860/crln.73.1.8693

Association of College and Research Libraries. (2015). Framework for information literacy for higher education. http://www.ala.org/acrl/sites/ala.org.acrl/files/content/issues/infolit/framework1.pdf

Bates, M. (2010). Information behavior. In M. J. Bates \& M. N. Maack (3 ${ }^{\text {rd }}$ ed., pp. 2381-2391) Encyclopedia of library and information sciences. CRC Press. https://pages.gseis.ucla.edu/faculty/bates/articles/information-behavior.html

Erdelez, S. (1999). Information encountering: It's more than just bumping into information. Bulletin of the American Society for Information Science, 25(3), 25-29. https://doi.org/10.1002/bult.118

Georgas, H. (2013). Google vs. the library: Student preferences and perceptions when doing research using Google and a federated search tool. Portal: Libraries and the Academy, 13(2), 165-185. https://www.doi.org/10.1353/pla.2013.0011

Girton, C. (2018). Showing students we care: Using empathetic marketing to ease library anxiety and reach distance students. Journal of Library \& Information Services in Distance Learning, 12(3), 209-218. https://doi.org/10.1080/1533290X.2018.1498634.

Go Beyond the Brochure. (2015). Whittier College-Ten things I wish I had known before attending. [Video]. YouTube. https://www.youtube.com/watch?v=z2ttdl6hEx4

Hassan, M. (2017). Information seeking behavior among undergraduates students engaged in Twitter. Journal of Pan African Studies, 10(10), 143. http://www.jpanafrican.org/docs/vol10no10/10.10-11-Musa.pdf

Karas, M. \& Green, R. (2007). The information needs and information-seeking behaviors of community college and lower-division undergraduate students. Community \& Junior College Libraries, 14(2), 103-109. https://doi.org/10.1300/02763910802139199

Kim, K. S., Sin, S. J., \& Yoo-Lee, E. Y. (2014). Undergraduates' use of social media as information sources. College \& Research Libraries, 75(4), 442-457. https://doi.org/10.5860/crl.75.4.442

Kuhlthau, C. C. (1991). Inside the search process: Information seeking from the user's perspective. Journal of the American Society for Information Science, 42(5), 361-371.

Nicholas, D., Huntington, P., Jamali, H., Rowlands, I., \& Fieldhouse, M. (2009). Student digital information-seeking behaviour in context. Journal of Documentation, 65(1), 106-132. https://doi.org/10.1108/00220410910926149

Palumbo, L. (2016). Championing institutional goals: Academic libraries supporting graduate women in STEM. The Journal of Academic Librarianship, 42(3), 192-199. https://doi.org/10.1016/j.acalib.2016.03.003

Selwyn, N., \& Gorard, S. (2016). Students' use of Wikipedia as an academic resource-Patterns of use and perceptions of usefulness. Internet and Higher Education, 28, 28-34. https://doi.org/10.1016/j.iheduc.2015.08.004

Trembach, S., \& Deng, L. (2018). Understanding millennial learning in academic libraries: Learning styles, emerging technologies, and the efficacy of information literacy 
instruction. College \& Undergraduate Libraries, 25(3), 297-315. https://doi.org/10.1080/10691316.2018.1484835

Whitmire, E. (2004). The relationship between undergraduates' epistemological beliefs, reflective judgment, and their information-seeking behavior. Information Processing \& Management, 40(1), 97-111. https://doi.org/10.1016/S0306-4573(02)00099-7 